\title{
Odor-based runway performance as a function of deprivation state, squad size, and subject-rotation procedures
}

\author{
MELANIE S. WEAVER, STEPHEN F. DAVIS, and SCOTT A. MOORE \\ Emporia State University, Emporia, Kansas
}

\begin{abstract}
The results of a two-phase experiment investigating odor-based alleyway performance of rats are reported. During both phases, two squads $(n=8)$ received daily double-alternation training. Each squad was composed of two subgroups $(n=4)$, one food deprived and one water deprived. The water-deprived animals were tested first in one squad, whereas the food-deprived animals were tested first in the second squad. During Phase 2, a daily subject-rotation procedure, under which the last subject in each of the second subgroups was rotated to the initial position in that subgroup, was implemented. Odor-based patterning was developed in Phase 1 only by the subgroup run last within each of the larger squads. Phase 2 rotation failed to disrupt patterned responding in the rotated animals. The results of this experiment support the contention that, even though specific deprivation conditions may have a bearing upon the use of odors as discriminative stimuli, such constraints are certainly not absolute.
\end{abstract}

Ludvigson and Sytsma (1967) demonstrated that rats can learn a double-alternation (DA) sequence of reward $(\mathrm{R})$ and nonreward $(\mathrm{N})$ by running fast on $\mathrm{R}$ trials and slow on $\mathrm{N}$ trials when they are tested under odormaximizing conditions, but not under odor-minimizing conditions. Odor-maximizing conditions typically involve the administration of $\mathrm{R}$ and $\mathrm{N}$ trials such that odors unique to a particular goal event are allowed to accumulate and act as discriminative cues for subsequent subjects. Such proposed $R$ and $N$ odors are not allowed to accumulate under odor-minimizing conditions. At present, data in this research area (e.g., Pitt, Davis, \& Brown, 1973) suggest that such odors are at least partially airborne. However, despite verification of $\mathbf{R}$ and $\mathrm{N}$ odors via single-cell recordings from mitral cells in the olfactory bulb (Voorhees \& Remley, 1981), their exact chemical structure and anatomical locus have yet to be determined.

As suggested, when rats are tested under odormaximizing conditions, odors will theoretically accumulate as additional subjects are tested. This prediction was recently verified by Prytula, Davis, and Fanning (1981). The results of this study indicated that animals tested earlier in the running sequence of a larger squad displayed weaker patterned responding than did animals tested later in the sequence. Furthermore, naive subjects introduced at the end of the running-order sequence, once patterning had been established by the original squad, developed patterned responding much sooner than did naive subjects introduced into earlier positions in the running order.

The authors' mailing address is: Department of Psychology, Emporia State University, Emporia, Kansas 66801.
Furthermore, past research (Davis, Prytula, Harper, Tucker, Lewis, \& Flood, 1974; Davis, Prytula, Noble, \& Mollenhour, 1976) has suggested that $\mathrm{R}$ and $\mathrm{N}$ odors produced under water deprivation may differ from $R$ and $\mathrm{N}$ odors produced under food deprivation. In these studies, runway-trained animals displayed patterned responding in the start and run sections of a straight runway only when their deprivation state coincided with that of startbox-placed odor-donor animals. However, data reported by Eslinger and Travis-Neideffer (1979) and Travis-Neideffer (1981) suggested that deprivationstate differences do not appear to impose absolute constraints upon the utilization of $\mathrm{R}$ and $\mathrm{N}$ odors. The present experiment was designed to investigate further the motivationally specific production and use of $\mathbf{R}$ and $\mathrm{N}$ odors by employing groups of animals composed of smaller subgroups being tested under different deprivation states. To avoid possible confounding due to reinforcer differences, all animals were administered the same type of reinforcer, a sucrose-water solution. The choice of this reinforcer was prompted by its previous use (Burns, DeHart, McRae, 1980; Burns, Dupree, \& Lorig, 1978) with food-deprived animals.

\section{METHOD}

\section{Subjects}

Sixteen, 90-day-old, male albino rats purchased from the Holtzman Company, Madison, Wisconsin, served as subjects. One week prior to pretraining, the animals were assigned randomly to either a food-deprivation (FD) or water-deprivation (WD) condition $(n=8)$. The FD subjects were placed on a regimen that maintained them at $85 \%$ of their free-feeding body weights, whereas the WD subjects were maintained on a $23-\mathrm{h}$ water-deprivation schedule. The subjects experiencing these conditions were further assigned randomly to subgroups of four animals each: two WD (Subgroups WDA and WDB) and two FD 
(Subgroups FDA and FDB). All animals were housed in individual cages and received their respective deprivation regimen following the daily experimental session. The deprivation schedules imposed at this time were maintained throughout the duration of experimental testing.

\section{Apparatus}

The apparatus consisted of a single straight runway $(11.4 \mathrm{~cm}$ wide $x 12.7 \mathrm{~cm}$ high) having a gray startbox $(28.1 \mathrm{~cm})$, a black run section $(91.4 \mathrm{~cm})$, and a black goalbox $(30.5 \mathrm{~cm})$. Guillotine doors separated the startbox and goalbox from the run section. Start, run, and goal latencies, produced by the activation of a microswitch located on the start door and the interruption of a series of photoelectric cells (located 15.2, 92.4, and $116.8 \mathrm{~cm}$, respectively, beyond the start door), were recorded on all trials. A plastic receptacle mounted into the end wall of the goalbox was modified to allow the external attachment of a plastic water bottle. The sipper tube of the water bottle extended into the receptacle, thus allowing the subject easy access but preventing water from dripping onto the goalbox floor. A thin sheet of transparent plastic covered the top of the runway to prevent odor dissipation.

\section{Procedure}

A four-day pretraining period immediately preceded experimental testing. On all pretraining days, all subjects received handling and taming, and habituation to the $32 \%$ sucrose-water reward solution in the home cage. On Day 3, each subject received a 5-min exploration period in the unbaited apparatus. The 4th pretraining day was the same as the $3 \mathrm{rd}$, with the exception that the apparatus was baited (i.e., water bottle containing sucrose-water solution was in place) and all photoelectric equipment was operative.

Prior to Phase 1 testing, the subgroups were combined to form two larger squads: Squad 1, composed of Subgroups FDA and WDB, and Squad 2, composed of Subgroups WDA and FDB. Hence, in Squad 1, four food-deprived animals preceded four water-deprived animals, whereas four water-deprived animals preceded four food-deprived animals in Squad 2. The animals within each main squad were tested in a fixed running order (Positions 1-8) on all days of Phase 1 (18 days, 144 trials).

On each day of Phase 2 ( 3 days, 24 trials), the animal in Position 8 (the last animal) was rotated to Position 5 , thus allowing an animal that normally followed three animals of the same deprivation state to follow four animals of the opposite deprivation state. None of the animals in each of the first subgroups were rotated during this phase.

During both phases of the experiment, each rat received its eight daily trials in a DA (RRNNRRNN) sequence. On each trial, the designated subject was removed from its home cage and placed into the startbox. Following a $3-\mathrm{sec}$ confinement, the start door was raised and the subject was allowed to traverse the runway. During all phases, the $R$ and $N$ events consisted of $3-\mathrm{sec}$ access to a full water bottle containing the sucrose-water solution and 30 -sec confinement to the goalbox with an empty water bottle in place, respectively. All daily trials were administered to a particular squad before the other squad had received its daily session. The order for running squads was alternated daily. All animals within a particular squad received Trial 1 before Trial 2 was administered, and so forth. The entire apparatus was swabbed twice with separate water-dampened sponges and was allowed to air dry for $5 \mathrm{~min}$ after the completion of each trial of each squad.

\section{RESULTS}

The eight daily latencies for each subject were reciprocated and multiplied by the appropriate metric constant to yield speed scores in meters per second.
Prior to analysis and graphing, the speed scores for the daily eight-trial DA sequence were combined as follows: the first two trials were averaged to yield an $R_{1}$ composite score, the next two trials were averaged to yield an $\mathrm{N}_{1}$ composite score, and so forth. Hence, the daily DA performance was reduced to four scores for each subject. These four scores were, in turn, used for graphing and analysis purposes.

Mean goal speeds for Squads 1 and 2 during Phase 1 are shown in Figures 1 and 2, respectively. Visual inspection of these figures indicates that both Subgroups FDB and WDB developed appropriate DA patterning in Phase 1, whereas Subgroups FDA and WDA failed to establish such appropriate responding. An analysis of variance incorporating two between-groups factors, deprivation condition (water deprived vs. food deprived) and position within the squad (Subgroup A vs. Subgroup $B$ ), and two within-groups factors, $R$ versus $N$, and days, was performed on the speed scores from the last 8 days of Phase 1 (the point at which appropriate patterning appeared to have been established by both of the B subgroups). The results of this analysis failed to yield significant effects for the start and run measures. However, the goal-measure analysis yielded significance for the deprivation condition $\mathrm{x}$ position within the squad $[F(1,12)=5.21, p<.05]$ and position within the squad

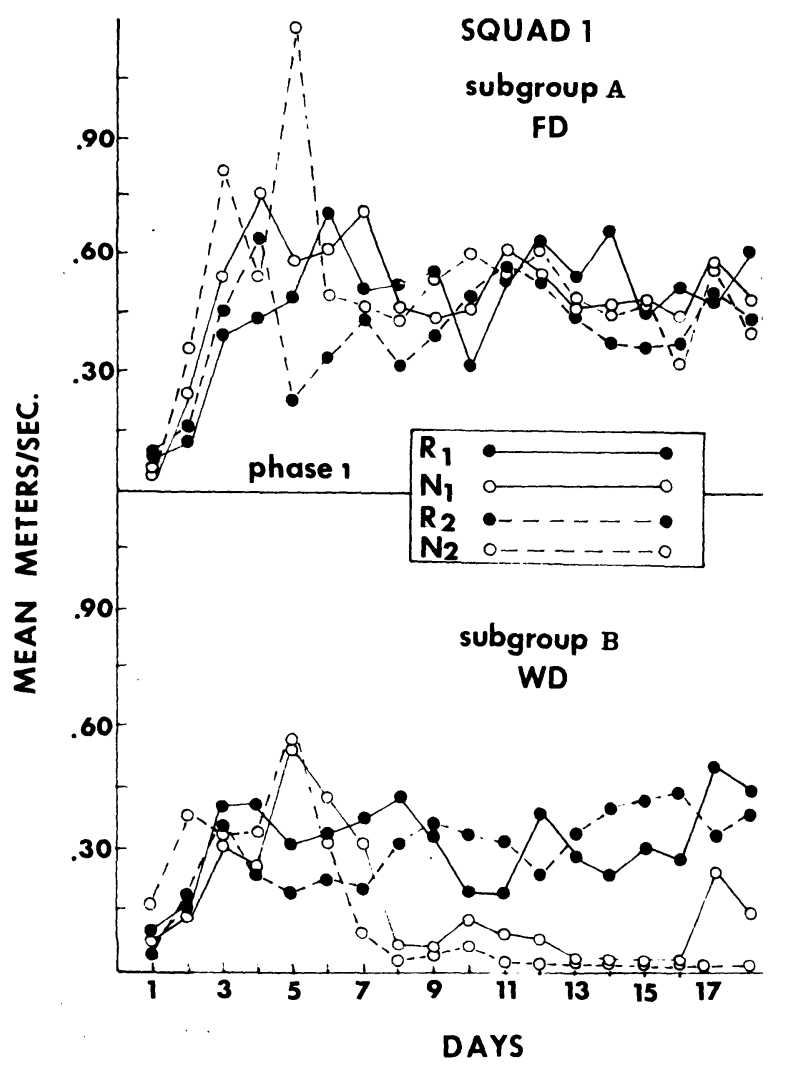

Figure 1. Mean goal speeds (in meters per second) for Squad 1, Subgroups A and B, during Phase 1. 


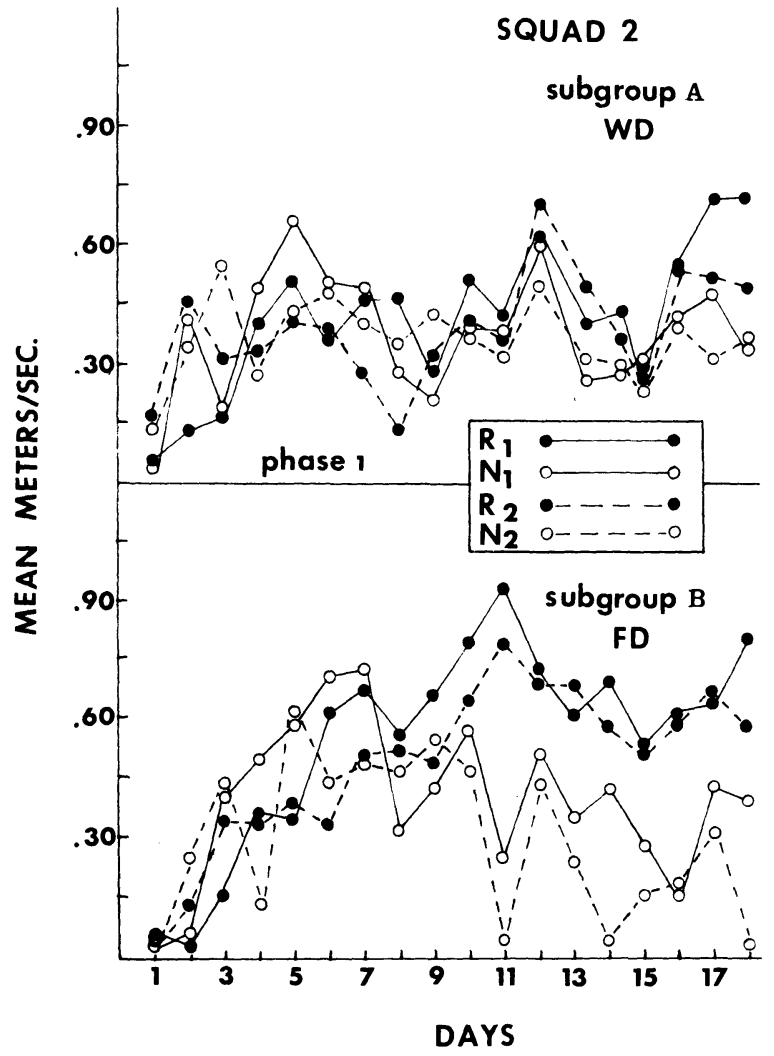

Figure 2. Mean goal speeds (in meters per second) for Squad 2, Subgroups A and B, during Phase 1.

$x$ R-N $[F(1,12)=7.56, p<.05]$ interaction effects. Subsequent Newman-Keuls tests indicated that Subgroup B in Squad 1 ran significantly $(p<.05)$ slower than did the three other subgroups and that significant $(p<.05) R$ versus $N$ differences were shown only by the second (B) subgroups in each squad.

As can be seen from Figure 3, appropriate goalmeasure patterning was maintained during Phase 2 by each of the rotated animals when they were tested in

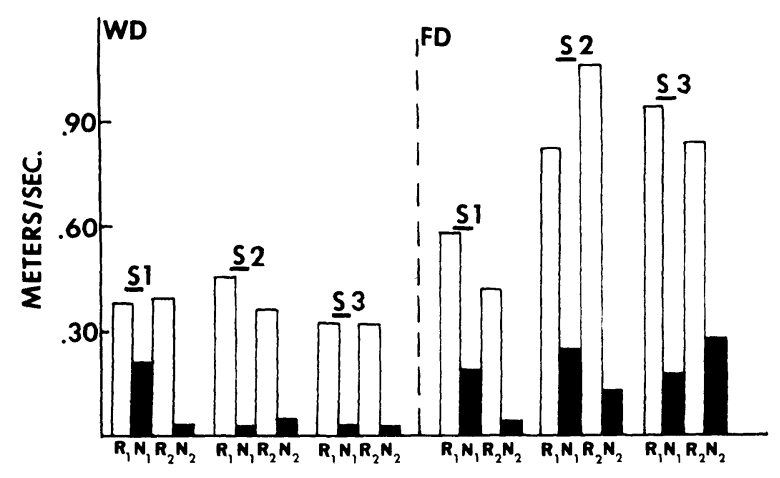

TRIALS

Figure 3. Daily goal speeds (in meters per second) for each of the rotated Subgroup B animals during Phase 2.
Position 5 (i.e., first animal in their respective subgroup). Because the subject-rotation procedure resulted in a daily change in the subject ordering, statistical analyses were not performed on the Phase 2 data.

\section{DISCUSSION}

The Phase 1 data might be interpreted as suggesting that Subgroup A in both squads did not exude odor cues that could be utilized by the subsequent, different-deprivation $B$ subgroups. Given this view, it would be assumed further that the patterning displayed by Subgroup B in both squads resulted from an accumulation of their own, within-subgroup odor cues. Obviously, if this view is espoused, then the lack of Phase 1 patterning in both A subgroups, which also contained four subjects, must be addressed. Furthermore, visual inspection of the Phase 1 data also indicated that the first subject in each of the B subgroups developed strong patterned responding. If one assumes that different deprivation states occasion the production of different odors, then this finding is not readily predictable.

Since Prytula et al. (1981) suggested that larger squads result in greater odor buildup, it might alternatively be argued that odor cues accumulated across all subjects within each of the larger squads in the present experiment, regardless of deprivation state. In particular, the A subgroups (Subjects 1-4) were run under theoretically low odor-buildup conditions, whereas the B subgroups (Subjects 5-8) would have been tested under higher odor-buildup conditions. Hence, due to the presence of less intense odor cues, Subgroup A in both squads might not be expected to develop patterned responding. Assuming that low odor-buildup conditions (four subjects) do not allow odors to accumulate sufficiently for the development of patterned responding, it would appear reasonable to suggest that the B subgroups, in turn, did not establish patterned responding solely on the basis of their own within-subgroup odor cues. A more plausible explanation would be that these subgroups developed double-alternation responding due to odors that had, in fact, accumulated over all eight subjects within each squad. This view, obviously, argues more for odor commonality than for odor specificity.

The results of the Phase 2 subject-rotation procedures also support the odor-commonality view. If $\mathrm{R}$ and $\mathrm{N}$ odors are completely deprivation-state specific, then the first subject in each of the different-deprivation B subgroups should not display odorbased patterning. This was certainly not the case during Phase 1 , and, as can be seen from Figure 2, also was not the case during Phase 2. Certainly the maintenance of appropriate responding by each one of the rotated animals supports some type of odor commonality across deprivation states.

Concerning the discrepancy between the present data suggesting odor commonality between different deprivation states and the previous studies (Davis et al., 1974; Davis et al., 1976) apparently demonstrating motivation specificity, the following points might be considered. First, a different reinforcer was employed for each deprivation state (i.e., food pellets for fooddeprived animals, water for water-deprived animals) in the previous studies, whereas a common reinforcer ( $32 \%$ sucrose) was administered to all subjects in the present experiment. This suggests the possibility that the type of reinforcer may interact with the specific deprivation state to influence odor production and/or utilization. Second, there are procedural differences between the studies. Whereas the previous studies (Davis et al., 1974 ; Davis et al., 1976) employed startbox-placed odor donors that did not traverse the runway, the A subgroup (donor) animals in the present study were allowed to make the complete instrumental response. Furthermore, the start and run sections of the apparatus were swabbed between each donorrun pair in the Davis et al. (1974) and Davis et al. (1976) studies, 
whereas swabbing procedures were employed in the present study only after the completion of a trial by an entire squad.

Even though the present data (see also Eslinger \& TravisNeideffer, 1979, and Travis-Neideffer, 1981) support odor commonality, the previously reported data (Davis et al., 1974; Davis et al., 1976; Travis-Neideffer, 1981) have indicated that the specific deprivation state may impose some constraints. Certainly, the considerations raised above point to future avenues that research in this area might take to help delineate the parameters relevant to the motivational specificity of odor cues.

\section{REFERENCES}

Burns, R. A., DeHart, P. J., \& McRae, H. L. (1980). Random and two-trial sequences of reward magnitudes. Bulletin of the Psychonomic Society, 16, 291-294.

Burns, R. A., DuPree, E. S., \& Lorig, T. S. (1978). Successive reductions of liquid and solid sucrose rewards. Bulletin of the Psychonomic Society, 12, 351-354.

Davis, S. F., Prytula, R. E., Harper, W. E., Tucker, H. K., LEw1S, C., \& Flood, L. (1974). Double-alternation runway performance as a function of inter- and intra-reinforcement odor cues. Psychological Reports, 35, 787-793.

Davis, S. F., Prytula, R. E., Noble, M. J., \& Mollenhour,
M. N. (1976). Motivational specificity of the signal value of odor cues. Animal Learning \& Behavior, 4, 407-410.

Eslinaer, P., \& Travis-Neidefrer, M. N. (1979). Utilization of odor cues as a function of like or unlike motivational-reward operations in donor and test rats. Paper presented at the meeting of the Southwestern Psychological Association, San Antonio, TX. Ludvigson, H. W., \& Sytsma, D. (1967). The sweet smell of success: Apparent double-alternation in the rat. Psychonomic Science, 9, 283-294.

PitT, S., Davis, S. F., \& Brown, B. R. (1973). Apparent double alternation in the rat: $\mathbf{A}$ failure to replicate. Bulletin of the Psychonomic Society, 2, 359-361.

Prytula, R. E., Davis, S. F., \& F anning, J. J. (1981). The acquisition of a running response as a function of odor buildup, squad rotation, and introduction of naive subjects. Animal Learning \& Behavior, 9, 556-560.

Travis-NeIdefFer, M. N. (1981). Overshadowing/generalization vs. preexperimental bias in utilization of motivation-specific odors in rats. Unpublished doctoral dissertation, Texas Christian University, Ft. Wort, TX.

VoORHeEs, J. W., \& REMLEY, N. R. (1981). Mitral cell responses to the odors of reward and nonreward. Physiological Psychology, 9, 164-170.

(Manuscript received for publication November 21, 1983.) 